\title{
Análise do grau de especialização da produção de cana- de-açúcar nos municípios goianos (2005 - 2015)
}

Analysis of the degree of specialization of sugarcane production in Goiás Municipalities (2005 - 2015)

\author{
Sabrina Faria de Queiroz ${ }^{\text {a }}$ \\ Matheus Silva de Godoi ${ }^{b}$ \\ Antônio Marcos de Queiroz ${ }^{c}$ \\ Cláudia Regina Rosal Carvalho ${ }^{d}$
}

\begin{abstract}
Resumo: O presente estudo analisa o grau de especialização e a concentração na produção de cana-de-açúcar dos municípios goianos, nos anos de 2005 e 2015 através do cálculo do quociente locacional (QL). Os resultados indicaram a manutenção de uma estrutura produtiva concentrada, em termos da produção de cana-de-açúcar, nas regiões mais centrais e desenvolvidas do estado de Goiás devido à crescente especialização daquela produção nos municípios das mesorregiões Sul goiano e Centro goiano, tradicionalmente mais dinâmicas economicamente. Esse efeito está associado, principalmente, aos incentivos fiscais oriundos do governo federal e estadual, melhores condições de infraestrutura daquelas mesorregiões, zoneamento agroecológico da cana e disponibilidade de mão de obra e de terras.
\end{abstract}

Palavras-chave: Cana-de-açúcar; Quociente Locacional; Goiás; Especialização Produtiva. Classificação JEL: R11; R12

\begin{abstract}
The present study analyzes the degree of specialization and the concentration in the production of sugar cane in the counties of Goiás, in the years 2005 and 2015 through the calculation of the locational quotient (QL). The results indicated the maintenance of a concentrated productive structure, in terms of sugar cane production, in the most central and developed regions of the state of Goiás due to the increasing specialization of that production in the counties of the south Goiás and central Goiás regions, traditionally more economically dynamic. This effect is mainly associated with tax incentives from the federal and state government, better infrastructure conditions in those mesoregions, agroecological zoning of sugarcane and availability of labor and land.
\end{abstract}

Keywords: Sugar cane; Locational Quotient; Goiás; Productive Specialization

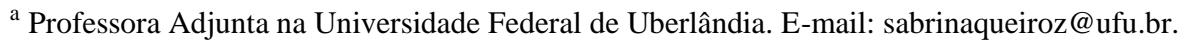

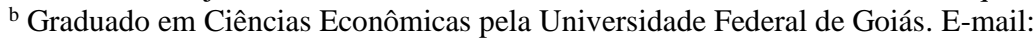

godoismatheus@gmail.com.

c Professor Adjunto na Universidade Federal de Goiás. E-mail: antonio.mq10@gmail.com.

${ }^{\mathrm{c}}$ Professora Associada na Universidade Federal de Goiás. E-mail:clregina@ hotmail.com.
} 


\section{Introdução}

Este trabalho tem o propósito de estudar o setor sucroalcooleiro goiano, pressupondo que a região passa por um momento de especialização da produção canavieira. Tal pressuposição está baseada em trabalhos realizados sobre o tema e informações de instituições como o Instituto Mauro Borges (IMB) e o Instituto Brasileiro de Geografia e Estatística (IBGE).

A análise da dinâmica econômica regional é de grande relevância, uma vez que, por meio dela é possível identificar fatores propulsores do crescimento ou do retrocesso econômico. A identificação destes fatores pode auxiliar a implementação de políticas públicas no sentido de reduzir a grande desigualdade regional ainda presente no Brasil.

A agropecuária tem papel fundamental na matriz produtiva do estado de Goiás desde a sua fundação, promovendo dinamismo econômico para a região. No início do século XXI, especificamente, a partir de 2003, aquele setor recebeu recursos do governo federal e incentivos fiscais do governo estadual para estimular a produção de álcool (etanol), visando suprir a demanda por um combustível alternativo aos derivados do petróleo. Em decorrência destas políticas, a economia goiana sofreu grandes transformações a partir da expansão da cultura da cana-de-açúcar no estado, entre elas: a especialização desta produção em municípios goianos; a dependência econômica de alguns municípios deste setor produtivo; e, o aprofundamento da desigualdade econômica.

Assim sendo, o principal objetivo deste trabalho é analisar a evolução do grau de especialização da produção de cana-de-açúcar, entre 2005 e 2015, em Goiás. A escolha em relação ao período de análise se justifica pela possibilidade de verificar alteração na dinâmica produtiva, proveniente principalmente da expansão desta cultura no período em que houve melhorias na infraestrutura regional decorrente dos investimentos do Plano de Aceleração do Crescimento (PAC), dos incentivos fiscais ao cultivo da cana-de-açúcar em Goiás e também pela disponibilidade de dados mais recentes.

Por meio da análise exploratória dos dados, trabalhamos com a hipótese de que existe uma especialização da produção de cana-de-açúcar nos municípios goianos. Logo, os objetivos específicos, que contribuem para o desenvolvimento do trabalho, são: avaliar a distribuição espacial da produção de cana-de-açúcar em Goiás; identificar os municípios em que houve mudança no setor produtivo em termos de maior ou menor especialização; e, finalmente, buscar indícios de possíveis fatores que induziram o deslocamento da produção agrícola nas regiões em que houve a confirmação da especialização.

Neste sentido, utilizamos dados secundários obtidos junto ao Instituto Mauro Borges (IMB) e Instituto Brasileiro de Geografia e Estatística (IBGE). O quociente locacional (QL), método de cálculo da especialização produtiva, é examinado a partir de tabelas e do mapeamento dos dados no território goiano. O indicador de especialização é empregado em análises de setores econômicos frequentemente presentes em pesquisas da área de economia regional.

Desta maneira, este trabalho está estruturado em quatro seções além desta introdução. Inicia-se pela apresentação do referencial teórico, que discorre sobre as Teorias 
de Desenvolvimento Regional, com a descrição dos trabalhos de August Lösch, Walter Isard, François Perroux, Gunnar Myrdal e Albert Hirschmann, citando de forma objetiva os pontos abordados pelos autores que serão úteis à construção da análise da especialização produtiva da cultura canavieira em Goiás. Além disso, realizamos um resgate histórico da formação da cadeia de cana-de-açúcar em Goiás, da sua importância econômica para a economia brasileira e também da formação da agropecuária e do setor sucroalcooleiro em Goiás, bem como uma análise da dimensão do setor em questão. Na terceira seção, apresentamos a descrição das variáveis utilizadas para o cálculo do QL, a metodologia do quociente locacional e a base de dados utilizada. Já, na quarta seção, explicamos os resultados obtidos pelo QL e sua distribuição espacial no território goiano. Por fim, na última seção, são descritas as considerações finais deste trabalho.

\section{Referencial Teórico}

Na presente seção, apresentamos as principais correntes teóricas que discutem a dinâmica da localização da atividade econômica. $\mathrm{O}$ texto buscou focalizar os aspectos centrais das teorias que auxiliam a análise do desenvolvimento regional, sendo importante para o entendimento da concentração e a dinâmica da produção da cana-de-açúcar em Goiás. Além dessa revisão teórica, foi desenvolvida uma análise da formação econômica de Goiás para entender o contexto em que a cana-de-açúcar surgiu como produto relevante para a economia, e como esta cultura adquiriu destaque no cenário nacional no período recente.

\subsection{Teorias de Desenvolvimento Regional}

O presente trabalho tem como base as teorias neoclássicas da localização e as teorias de desenvolvimento regional. A respeito deste campo da teoria econômica, existem diversos teóricos que suscitaram o debate dos fatores que impulsionam o desenvolvimento ou não de uma região, isto é, a dinâmica regional. Entre eles, podemos citar August Lösch, Walter Isard, François Perroux, Gunnar Myrdal e Albert Hirschmann.

Para analisar os aspectos do desenvolvimento regional, é necessário compreender o próprio conceito de região. Segundo Haddad (1989), a economia regional pode ser compreendida como um campo de estudo da economia espacial, podendo esta ser dividida em duas abordagens: a locacional e a regional. Neste sentido, a abordagem locacional abrange um campo próximo da microeconomia, em que as decisões ocorrem em uma unidade econômica em um espaço econômico contínuo. Enquanto isso, a abordagem regional é mais próxima da macroeconomia abrangendo subespaços contínuos do espaço regional, estando preocupada com as aglomerações econômicas, políticas, sociais e administrativas inter-relacionadas.

A partir deste conceito de região, podemos iniciar a apresentação do debate teórico a respeito da localização de uma determinada empresa. August Lösch buscou analisar a ordem espacial da economia mostrando como uma empresa, em uma localização definida 
e a um determinado custo médio, produz seu produto e vende no mercado até uma distância em que o custo de transporte mais o custo de produção sejam iguais ao preço do produto no mercado. É definido o limite para a localização de uma firma e da sua área de atuação a partir do ponto em que o lucro se torna zero. Assim, este ponto também será o de lucro zero para outra empresa localizada em outra área. Desta forma, o mercado entrará em equilíbrio quando todas as empresas estiverem em uma localização ótima, ou seja, não penetraram na área de mercado de outra empresa (SOUZA, 2009).

De forma complementar, Walter Isard examina a concentração, a dispersão populacional das atividades econômicas através de sua pesquisa sobre a localização e a economia espacial das unidades produtivas. Este autor sugere que são vários os fatores que afetam a dispersão ou a concentração dos fatores produtivos como o crescimento demográfico, fatores tecnológicos, subutilização de recursos naturais ou fatores econômicos. Consequentemente, para o estudo econômico de uma região, devem ser incluídas as características sociais, demográficas e tecnológicas na análise, e não somente o ponto de vista econômico. Logo, ocorre um processo contínuo de ajustamento dos fatores de produção, seja de aglomeração ou de dispersão, dado o dinamismo das variáveis, até um ponto ótimo regional e, em seguida, um ponto ótimo global (SOUZA, 2009).

Além dos fatores produtivos listados anteriormente, a produção industrial se concentra em regiões com boas vias de transporte, alta densidade demográfica e disponibilidade de recursos naturais, criando um polo de crescimento. Porém, as indústrias começam a se dispersar quando os terrenos ficam escassos e caros, e as leis trabalhistas e ambientais se tornam mais rígidas. Por outro lado, um local com poucos fatores produtivos não promoverá o desenvolvimento das atividades econômicas ou elas se dispersarão.

François Perroux, autor da Teoria dos Polos de Crescimento, ainda sugere que o desenvolvimento não acontece de forma homogênea no território, mas de forma heterogênea e desigual através de uma indústria motriz. Esta teoria busca analisar os motivos que fazem com que o crescimento econômico não siga o previsto no modelo neoclássico, já que algumas regiões e setores econômicos crescem acima da média, enquanto outros permanecem estagnados ou com baixo crescimento. $\mathrm{O}$ estudo realizado por Perroux supõe a formação de polos econômicos principais e secundários, hierarquizados segundo a influência econômica (SOUZA, 2009). Assim, de acordo com Perroux (1977, p. 146) apud Souza (2009, p. 55-56), “[...] crescimento não aparece simultaneamente em toda a parte. Ao contrário, manifesta-se em pontos ou polos de crescimento, com intensidades variáveis, expande-se por diversos canais e com efeitos variáveis sobre toda a economia".

Avançando no debate sobre economia regional, o economista sueco Gunnar Myrdal, ao investigar as razões da desigualdade no desenvolvimento entre regiões e os motivos que fazem com que ela aumente, encontrou variáveis como produtividade de um setor, a renda média da população, poupança e investimento diretamente relacionados com o desenvolvimento regional. $\mathrm{O}$ autor ainda notou que há uma propensão à manutenção da desigualdade e uma tendência a que haja um efeito cumulativo, na medida em que regiões decadentes, com baixo nível educacional e baixa produtividade, tendem a continuar 
reproduzindo um baixo dinamismo econômico, com renda média da população, poupança e investimento estagnado ou em declínio. Paralelamente, Myrdal aponta para a existência de ciclos cumulativos, ou seja, um local com nível de produtividade decrescente tenderá a se manter em condição de desigualdade, entrando assim em um ciclo vicioso. Por outro lado, um local com alto nível educacional e, consequentemente, alta produtividade, entrará em um ciclo cumulativo de menor desigualdade e maior desenvolvimento (LIMA; SIMÕES, 2009).

Ainda, de acordo com Myrdal (1968, p. 32) apud Souza (2009, p. 141), "o processo acumulativo, quando não controlado, promoverá desigualdades crescentes". Conforme mencionado, existirá um círculo vicioso no qual uma região ascendente e outra descendente, tendem a permanecerem nele em um processo cumulativo, que Myrdal nomeou de causação circular cumulativa (SOUZA, 2009).

De acordo com Lima e Simões (2009, p. 13) "o objetivo da Teoria da Causação Circular Cumulativa seria então analisar as inter-relações causais de um sistema social enquanto o mesmo se movimenta sobre a influência de questões exógenas". Deste modo, a teoria de Myrdal pode ser utilizada para explicar diversas questões sociais como, por exemplo, o deslocamento populacional e industrial.

Dando continuidade à linha teórica de Gunnar Myrdal, Albert Hirschmann verificou as influências de uma região desenvolvida e de uma região em desenvolvimento, tentando identificar os efeitos que permitem o crescimento de uma região, os quais ele chamou de efeitos para frente ou propulsores, e os efeitos para trás ou regressivos, aqueles que causam retrocesso.

Assim, os efeitos propulsores de uma região com alto grau de crescimento podem provocar aumento da demanda por produtos de uma região com baixo crescimento, gerando aumento da remuneração dos fatores de produção desta região. No entanto, também são gerados efeitos regressivos como evasão de capitais, trabalhadores e empresas da região menos desenvolvida, podendo ampliar as desigualdades entre as regiões. $\mathrm{O}$ autor propõe a neutralização dos efeitos regressivos mediante a implantação de infraestrutura e de atividades produtivas nas regiões que apresentam baixo crescimento, buscando assim maior equidade e eficiência (SOUZA, 2009).

Em suma, as teorias de desenvolvimento regional buscam verificar os fatores que contribuem para o desenvolvimento econômico e social de uma região, fatores aglomerativos e desaglomerativos que vão desde as características físicas da região a efeitos que uma região transmite para outra. Todavia, ao analisar uma região em específico é provável que ocorra diversos fatores indutores do desenvolvimento ao mesmo tempo.

\subsection{Resgate histórico da formação da cadeia de cana-de-açúcar em Goiás e sua importância para a economia brasileira}

Na presente seção, abordamos a formação histórica da produção de cana-de-açúcar no estado de Goiás, começando pelo desenvolvimento da agropecuária e, em seguida, identificando as variáveis que podem favorecer a especialização da produção. Para isto, a 
seção está dividida em três partes. Na primeira parte, analisamos a formação da agropecuária goiana no século XVIII ao século XX. Na segunda parte, descrevemos a formação econômica da cadeia de cana-de-açúcar goiana. Finalmente, na terceira parte, fazemos uma análise da dimensão do setor canavieiro goiano no período de 2005-2015.

\subsubsection{Formação Agropecuária Goiana}

A formação econômica de Goiás sempre esteve ligada ao desenvolvimento econômico do estado brasileiro. Assim, a agropecuária, em Goiás, surgiu como uma atividade econômica secundária e com o objetivo de apoiar a mineração no século XVIII.

Estevam (2004), ao estudar a formação agrícola em Goiás, verificou a procura por ouro no século XVIII como precursora para a ocupação da região, sendo o início da extração mineral concomitante à exploração das terras pela agropecuária. Embora 0 crescimento da agropecuária goiana tenha ocorrido de forma mais expressiva somente no século XX.

Com o declínio da mineração, a agropecuária se consolidou como atividade econômica principal, sendo uma atividade de subsistência. Nas palavras de Estevam (2004, p. 27), "a tendência da população era voltar-se para a lavoura, fundando estabelecimentos de lavoura e criação." Neste período, a sociedade goiana ficou apartada das transformações que ocorreram no país, consolidando sua estagnação econômica.

Segundo Estevam (2004), com o declínio do ciclo da mineração, a população migrou para outras regiões do país, e outra parte se estabeleceu no meio rural, conduzindo a Província de Goiás ao isolamento político, social e econômico. A unidade básica de produção passou a ser a fazenda de gado, viabilizada pelo uso extensivo de terra, pouca mão de obra e trabalho familiar.

No século XX, com a crise de superprodução do café, Goiás iniciou seu processo de integração nacional através do fim do modo de produção "voltado para fora". De acordo com Gremaud, Vasconcelos e Toledo Jr. (2007), a queda da rentabilidade do setor cafeeiro ocasionou o deslocamento dos investimentos para outros setores, principalmente para a indústria. Entre as políticas do governo federal existiam projetos e planos nacionais que buscavam a integração nacional e a interiorização da economia, destacando-se a "Marcha para o Oeste", que buscou incentivar o progresso no interior do país.

O desenvolvimento goiano, após 1930, ocorreu com a expansão da fronteira agrícola estimulada pela industrialização da região Sudeste do Brasil. Assim, a produção de bens primários cresceu e alcançou todas as demais regiões brasileiras. Contudo, este processo implementou um novo padrão na economia através de uma nova divisão inter-regional do trabalho (BORGES, 1996).

Durante o governo do presidente Juscelino Kubitschek (1956-1961), a região CentroOeste foi integrada ao país através do Plano de Metas e da construção de Brasília. O Plano de Metas visava a produção de bens de consumo duráveis, construção de infraestrutura e produção de bens intermediários para novos setores e assim combater os estrangulamentos que havia na economia nacional (GREMAUD, VASCONCELOS; TONETO JR., 2007). O 
estado de Goiás foi especialmente beneficiado por meio da construção de Brasília, da usina hidroelétrica de Cachoeira Dourada e de diversas vias de transporte rodoviário ligando o território goiano ao restante do país.

Segundo Dias (2013), o governo federal incentivou o desenvolvimento agrícola através de políticas creditícias que financiavam investimentos a juros baixos, conduzindo à "revolução verde" após o governo do presidente Juscelino Kubitschek. O mercado agrícola também recebeu incentivos governamentais que visaram reduzir o risco da produção agrícola, como as Políticas de Garantia de Preços Mínimos (PGPM), as aquisições do governo federal (AGF) e os empréstimos do governo federal (EGF), promovendo o desenvolvimento do setor agrícola brasileiro.

Considerando o que foi até agora mencionado, evidencia-se uma notável expansão da capacidade produtiva do estado de Goiás, principalmente na segunda metade do século $\mathrm{XX}$, o que levou à construção de uma estrutura agroindustrial dinâmica e desenvolvida.

\subsubsection{Formação Econômica da Cadeia de Cana-de-Açúcar em Goiás}

Na década de 1970, em razão dos dois choques mundiais do petróleo, o governo federal revisou sua política energética, esforçando-se para reduzir a dependência da matriz energética nacional em relação ao setor externo. Entre os programas federais implementados, estava a ampliação do setor sucroalcooleiro brasileiro e seu avanço sobre outras regiões do país através do lançamento e depois do reforço do "Programa Nacional do Álcool" (PNA ou Proálcool) (ABDALA; RIBEIRO, 2011).

No mesmo período, a expansão da produção de cana-de-açúcar em Goiás ficou dividida em quatro fases ligadas ao Proálcool. Segundo Abdala e Ribeiro (2011), a primeira fase se iniciou em 1974 e terminou em 1986, ocorrendo apenas um tímido crescimento da produção de cana-de-açúcar em Goiás, em que se destacaram os municípios de Santa Helena e Goianésia.

Na segunda fase, que compreendeu dos anos de 1979 a 1986, a produção da canade-açúcar alcançou as áreas do Sul até o Norte de Goiás, motivada particularmente pela infraestrutura que havia nesta região para o escoamento da produção para o estado de São Paulo. Na terceira fase do Proálcool, de 1986 a 1995, foi realizada a desregulamentação do setor a nível nacional em defesa da livre concorrência. Na quarta fase do Proálcool, período entre 2003 e os dias atuais, o estado de Goiás ficou conhecido principalmente pela ampliação da produção de cana-de-açúcar, em decorrência principalmente da popularização dos carros movidos a biocombustíveis (QUEIROZ, 2016).

Vian (2015) enfatiza que as maiores empresas, localizadas em regiões em que o crescimento do setor já estava saturado, como é o caso de São Paulo, padecem de problemas como deseconomias de escala em transporte de cana-de-açúcar e não tem condições de investir na ampliação da capacidade instalada, já que apresentam elevada capacidade ociosa. Em contrapartida, as empresas localizadas nas áreas de fronteira são beneficiadas pelo maior crescimento da atividade, propícias à maior mecanização das áreas, como é caso dos estados de Mato Grosso, Mato Grosso do Sul, Goiás, Paraná e em Minas Gerais. 
Goiás se beneficiou da exploração da cana-de-açúcar devido a disponibilidade de terras, conhecimento da produção, infraestrutura e demanda consolidada na quarta da fase do Proálcool. Deste modo, o desenvolvimento da cultura da cana-de-açúcar ocorreu de forma mais extensiva do que intensiva.

Segundo Castro et al. (2010), a monocultura da cana-de-açúcar se intensificou a partir de 2007, a partir da elevação da área plantada, justamente de maneira oposta aos discursos políticos que defendiam que a cultura da cana-de-açúcar se instalaria primeiro em áreas degradadas, conforme previa o zoneamento agroecológico da cana-de-açúcar. Entretanto, a expansão sucedeu através da conversão de áreas agrícolas e de pastagens, e não pela melhoria da produtividade. Conforme Nassar et al. (2008), a competição entre as culturas no Cerrado, entre o milho e a soja com a cana-de-açúcar e entre a pecuária e canade-açúcar, tem deslocado a fronteira agrícola, principalmente, por meio da ocupação de áreas antes ocupadas pela pecuária.

Ademais, a expansão canavieira foi impulsionada pela demanda no Brasil e no exterior, com o objetivo de reduzir a dependência de combustíveis fósseis. O governo federal e o governo estadual buscaram incentivar a produção dos biocombustíveis através, sobretudo, de incentivos fiscais em todo o processo produtivo. Deste modo, houve, particularmente na primeira década do século XXI, aumento expressivo da produção de cana-de-açúcar para a produção de biocombustível (QUEIROZ, 2016).

A demanda por álcool, utilizado como combustível nos veículos nos mercados nacionais e internacionais, estimulou os produtores de cana-de-açúcar a explorarem novas terras. Nesta conjuntura, Goiás se tornou um estado atrativo para a agricultura comercial da cana-de-açúcar, aproveitando e desenvolvendo a agricultura nas áreas de melhor infraestrutura, mecanização e conhecimento técnico. Por conseguinte, aconteceu uma melhora do biocombustível produzido, o que possibilitou a ampliação da produção para atender a demanda em questão (ABDALA; RIBEIRO, 2011).

Sauer e Pietrafesa (2012) e Queiroz (2016) analisaram, entre outros temas, o financiamento público da expansão da produção da cana-de-açúcar, verificando o financiamento da expansão do setor canavieiro através da redução de regulações fiscais e ambientais, acompanhado de financiamento direto a indústrias e infraestrutura. Instituições como o Banco Nacional do Desenvolvimento Econômico e Social (BNDES), o Fundo Constitucional do Centro-Oeste (FCO) e o programa PRODUZIR destinaram (e destinam) recursos com baixa taxa de juros, longos períodos de carências e prazos facilitados para amortizar os empréstimos, objetivando a consolidação do setor sucroalcooleiro goiano.

Assim, na primeira década do século XXI, conhecida como quarta fase do Proálcool, Goiás se destacou entre os estados membros da Federação pelo aumento expressivo da produção de cana-de-açúcar, através de um processo apoiado e mantido por incentivos ficais, créditos e utilização de insumos modernos na produção. Logo, a economia goiana se consolidou como uma das principais representantes da cultura da cana-de-açúcar para fins comerciais. 


\subsubsection{Análise da dimensão do setor canavieiro goiano no período recente}

O setor sucroalcooleiro é de grande importância para a economia brasileira por sua contribuição para o desenvolvimento socioeconômico. Goiás é o segundo maior produtor de cana-de-açúcar do Brasil, ficando atrás somente do estado de São Paulo. Além disso, o Brasil se destaca por ser um dos maiores exportadores deste produto. Esta expressiva dimensão e importância do setor canavieiro serão avaliados através dos dados apresentados em seguida.

Conforme observamos na tabela 1, uma grande distância separa as dimensões do setor canavieiro paulista e goiano. Enquanto a área colhida de cana-de-açúcar em São Paulo situa-se ao redor de $55 \%$ (de toda área colhida no Brasil), em Goiás ela não alcança $10 \%$. Apesar disso, é preciso salientar que houve um crescimento significativo da dimensão do setor canavieiro em Goiás, uma vez que ele representava somente 3,4\% da área colhida brasileira em 2005 e quase triplicou sua participação em 2015.

Tabela 1: Área Colhida de Cana-de-Açúcar no Brasil, Goiás e em São Paulo (Hectares - ha) e área relativa Goiás/Brasil e São Paulo/Brasil (\%) - 2005 a 2015

\begin{tabular}{c|c|c|c|c|c}
\hline \hline Ano & $\begin{array}{c}\text { Área } \\
\text { Colhida } \\
\text { (Brasil) }\end{array}$ & $\begin{array}{c}\text { Área } \\
\text { Colhida } \\
\text { (Goiás) }\end{array}$ & $\begin{array}{c}\text { Relação } \\
\text { Goiás/Brasil } \\
(\%)\end{array}$ & $\begin{array}{c}\text { Área } \\
\text { Colhida (São } \\
\text { Paulo) }\end{array}$ & $\begin{array}{c}\text { Relação São } \\
\text { Paulo/Brasil } \\
(\%)\end{array}$ \\
\hline 2005 & 5.805 .518 & 196.596 & $3.38 \%$ & 3.084 .752 & $53.13 \%$ \\
\hline 2006 & 6.355 .498 & 232.577 & $3.65 \%$ & 3.495 .893 & $55 \%$ \\
\hline 2007 & 7.080 .920 & 278.000 & $3.92 \%$ & 3.890 .414 & $54.94 \%$ \\
\hline 2008 & 8.140 .089 & 401.100 & $4.92 \%$ & 4.530 .784 & $55.66 \%$ \\
\hline 2009 & 8.617 .555 & 523.808 & $6.07 \%$ & 4.781 .465 & $55.48 \%$ \\
\hline 2010 & 9.076 .706 & 578.666 & $6.37 \%$ & 4.986 .634 & $54.93 \%$ \\
\hline 2011 & 9.601 .316 & 697.541 & $7.26 \%$ & 5.205 .841 & $54.22 \%$ \\
\hline 2013 & 9.705 .388 & 732.870 & $7.55 \%$ & 5.150 .461 & $53.06 \%$ \\
\hline 2014 & 10.195 .166 & 860.482 & $8.44 \%$ & 5.399 .235 & $52.95 \%$ \\
\hline 2015 & 10.111 .376 & 930.052 & $9.19 \%$ & 5.527 .560 & $54.66 \%$ \\
\hline \hline
\end{tabular}

Fonte: Elaboração própria com base nos dados do IBGE.

A mesma tendência de crescimento pode ser verificada na quantidade produzida, conforme evidenciado na tabela 2. Observa-se o aumento da área colhida, e da produção total de cana-de-açúcar, alcançando 750.290.277 toneladas em 2015. Em Goiás, a produção aumentou de 15.642.125 para 72.066.835 toneladas, enquanto em São Paulo a produção 
foi de 254.809.756 para 423.419.511 toneladas no período analisado. Embora Goiás tenha apresentado crescimento da produção da cana-de-açúcar em torno de $460 \%$ e São Paulo de $166 \%$, o estado de São Paulo continuou como o maior produtor de cana-de-açúcar, devido a modernização agrícola e a expansão da área colhida. Contudo, é importante considerar que Goiás aumentou a sua participação na produção nacional, passando de 3,44\% em 2005 para $9,6 \%$ em 2015.

Tabela 2: Quantidade Produzida de Cana-de-Açúcar no Brasil, Goiás e São Paulo (Toneladas) e percentual relativo Goiás/Brasil e São Paulo Brasil (\%) - 2005 a 2015

\begin{tabular}{c|c|c|c|c|c}
\hline \hline Ano & $\begin{array}{c}\text { Quantidade } \\
\text { (Brasil) }\end{array}$ & $\begin{array}{c}\text { Quantidade } \\
\text { (Goiás) }\end{array}$ & $\begin{array}{c}\text { Relação } \\
\text { Goiás/Brasil (\%) }\end{array}$ & $\begin{array}{c}\text { Quantidade } \\
\text { (São Paulo) }\end{array}$ & $\begin{array}{c}\text { Relação São } \\
\text { Paulo/Brasil (\%) }\end{array}$ \\
\hline 2005 & 422.956 .646 & 15.642 .125 & $3.69 \%$ & 254.809 .756 & $60.24 \%$ \\
\hline 2006 & 477.410 .655 & 19.049 .550 & $3.99 \%$ & 289.299 .376 & $60.59 \%$ \\
\hline 2007 & 549.707 .314 & 22.387 .847 & $4.07 \%$ & 329.095 .578 & $59.86 \%$ \\
\hline 2008 & 645.300 .182 & 33.112 .209 & $5.13 \%$ & 386.061 .274 & $59.82 \%$ \\
\hline 2009 & 691.606 .147 & 43.666 .585 & $6.31 \%$ & 408.451 .088 & $59.05 \%$ \\
\hline 2010 & 717.463 .793 & 48.000 .163 & $6.69 \%$ & 426.572 .099 & $59.45 \%$ \\
\hline 2011 & 734.006 .059 & 54.903 .085 & $7.47 \%$ & 427.364 .854 & $58.22 \%$ \\
\hline 2012 & 721.077 .287 & 58.348 .797 & $8.09 \%$ & 406.152 .815 & $56.32 \%$ \\
\hline 2014 & 768.090 .444 & 69.376 .714 & $9.03 \%$ & 434.079 .735 & $56.51 \%$ \\
\hline 2015 & 750.290 .277 & 72.066 .835 & $9.60 \%$ & 423.419 .511 & $56.43 \%$ \\
\hline \hline
\end{tabular}

Fonte: Elaboração própria com base nos dados do IBGE.

Quando se considera questões de produtividade, os dois estados apresentam rendimento médio bem próximos, mas acima do nível nacional. Ou seja, enquanto o rendimento médio da produção brasileira de cana-de-açúcar oscila entre 70 e $80 \mathrm{mil}$ kg por hectare (kg/ha), Goiás e São Paulo apresentam níveis acima de $75 \mathrm{mil} \mathrm{kg} / \mathrm{ha}$, o que representa, no mínimo, $3 \%$ a mais de produtividade do que a média nacional. Isto pode ser observado na tabela 3 a seguir.

No período analisado, embora tenha ocorrido ampliação da área colhida e aumento da produtividade advindos da modernização agrícola, o rendimento médio da produção apresenta redução nos estados considerados. Em Goiás, o rendimento médio reduziu 4,3\% e em São Paulo 8,9\%. Mas, mesmo assim, foram mais rentáveis que o apresentado pelo Brasil nos anos de 2005 a 2015. Segundo Batista (2008), o rendimento da produção de cana-de-açúcar recuou devido ao aumento das chuvas no Centro-Sul, deixando a cana-deaçúcar com mais água e, portanto, com menos concentração de açúcar. 


\section{Tabela 3: Rendimento Médio (Kg/ha) e Rendimento Relativo (\%) da Produção de Cana-de-Açúcar no Brasil, Goiás e São Paulo - 2005 a 2015}

\begin{tabular}{c|c|c|c|c|c}
\hline \hline Ano & $\begin{array}{c}\text { Rendimento } \\
\text { Médio (Brasil) }\end{array}$ & $\begin{array}{c}\text { Rendimento } \\
\text { Médio (Goiás) }\end{array}$ & $\begin{array}{c}\text { Relação } \\
\text { Goiás/Brasil } \\
\mathbf{( \% )}\end{array}$ & $\begin{array}{c}\text { Rendimento } \\
\text { Médio (São } \\
\text { Paulo) }\end{array}$ & $\begin{array}{c}\text { Relação São } \\
\text { Paulo/Brasil (\%) }\end{array}$ \\
\hline 2005 & 72.854 & 79.564 & $109.21 \%$ & 82.602 & $113.38 \%$ \\
\hline 2006 & 75.117 & 81.906 & $109.03 \%$ & 82.754 & $110.16 \%$ \\
\hline 2007 & 77.632 & 80.531 & $103.73 \%$ & 84.591 & $108.96 \%$ \\
\hline 2008 & 79.274 & 82.553 & $104.13 \%$ & 85.208 & $107.48 \%$ \\
\hline 2009 & 80.255 & 83.363 & $103.87 \%$ & 85.423 & $106.43 \%$ \\
\hline 2010 & 79.044 & 82.949 & $104.94 \%$ & 85.543 & $108.22 \%$ \\
\hline 2011 & 76.448 & 78.709 & $102.95 \%$ & 82.093 & $107.38 \%$ \\
\hline 2012 & 74.297 & 79.617 & $107.16 \%$ & 78.858 & $106.13 \%$ \\
\hline 2013 & 75.339 & 80.625 & $107.01 \%$ & 80.397 & $106.71 \%$ \\
\hline 2014 & 70.646 & 78.396 & $110.97 \%$ & 72.103 & $102.06 \%$ \\
\hline 2015 & 74.203 & 77.487 & $104.42 \%$ & 76.602 & $103.23 \%$ \\
\hline \hline
\end{tabular}

Fonte: Elaboração própria com base nos dados do IBGE.

Em relação à dimensão do setor canavieiro em Goiás, realizamos uma análise de quais são os principais produtos da lavoura temporária cultivados em 2017. Os dados do censo agropecuário de 2017 permitiram identificar que a cana-de-açúcar, milho e a soja são os três produtos da lavoura temporária mais produzidos em Goiás, responsáveis por $96,5 \%$ da produção total em toneladas. A partir disto, verificou-se, segundo dados do Instituto Mauro Borges (2018), que a cana-de-açúcar se destaca entre eles por representar 61,39\% em 2005 e 79,91\% em 2015. Ou seja, no mesmo período, o milho foi de $11,2 \%$ para $10,55 \%$ e a soja de $27,41 \%$ para $9,54 \%$. A redução da participação do milho e, principalmente, da soja na produção total, demonstra a dinâmica da substituição de culturas que ocorreu neste período em Goiás. A evolução da produção destes produtos agrícolas é representada a seguir na tabela 4, em termos percentuais.

Quando analisamos a participação de Goiás em culturas selecionadas, como a canade-açúcar, é importante considerar a atuação da Empresa Brasileira de Pesquisa Agropecuária (Embrapa), que elaborou o Zoneamento Agroecológico da Cana-de-açúcar ( ZAEcana), de acordo com o Decreto $n^{\circ}$ 6.961, de setembro de 2009, com o objetivo de subsidiar, por meio de informações técnicas, a formulação de políticas públicas para a expansão e a produção de cana-de-açúcar de forma sustentável no Brasil ${ }^{1}$. De acordo com

2 Ver Zoneamento Agroecológico da Cana, em: <http://www.agricultura.gov.br/arq_editor/file/ Desenvolvimento_Sustentavel/Agroenergia/Orientacoes_Tecnicas/ZAE_Cana.pdf. 
os critérios do ZAEcana, grande parte das novas áreas de expansão canavieira está localizada na região Centro-Oeste, já que disponibiliza de condições favoráveis de clima e de meio ambiente. Ademais, oferecem grande diversidade e qualidade genética para suas lavouras, esperando elevados ganhos de produtividade e, consequentemente, redução do custo de produção no médio prazo (MANZATTO et al., 2009).

Tabela 4: Produção de Culturas Selecionadas no Estado de Goiás $(\%)^{2}-2005$ a 2015

\begin{tabular}{c|c|c|c|c|c|c|c|c|c|c|c}
\hline \hline Culturas & $\mathbf{2 0 0 5}$ & $\mathbf{2 0 0 6}$ & $\mathbf{2 0 0 7}$ & $\mathbf{2 0 0 8}$ & $\mathbf{2 0 0 9}$ & $\mathbf{2 0 1 0}$ & $\mathbf{2 0 1 1}$ & $\mathbf{2 0 1 2}$ & $\mathbf{2 0 1 3}$ & $\mathbf{2 0 1 4}$ & $\mathbf{2 0 1 5}$ \\
\hline Cana & 61.39 & 67.16 & 68.58 & 74.05 & 78.89 & 79.81 & 80.33 & 77.82 & 80.69 & 79.56 & 79.91 \\
\hline Milho & 11.2 & 11.62 & 12.96 & 11.31 & 8.92 & 8.13 & 8.4 & 10.98 & 8.94 & 10.31 & 10.55 \\
\hline Soja & 27.41 & 21.22 & 18.46 & 14.64 & 12.19 & 12.06 & 11.27 & 11.2 & 10.37 & 10.14 & 9.54 \\
\hline Total & 100 & 100 & 100 & 100 & 100 & 100 & 100 & 100 & 100 & 100 & 100 \\
\hline \hline
\end{tabular}

Fonte: Elaboração própria com base nos dados do Instituto Mauro Borges.

Shikida (2013) afirma que 46,59\% das terras aptas ao plantio de cana-de-açúcar estão localizadas na região Centro-Oeste por possuir boas condições edafoclimáticas (clima, solo e recursos hídricos favoráveis ao cultivo da cana-de-açúcar), justificando o processo de expansão da produção de cana-de-açúcar nessa região. A tabela 5 mostra as áreas aptas à expansão do cultivo de cana-de-açúcar na região Centro-Oeste. Goiás responde pela maior área apta para expansão, com cerca de 12,6 milhões de hectares, seguido pelo Mato Grosso do Sul, com 10,8 milhões de hectares, e Mato Grosso, com 6,81 milhões de hectares.

Tabela 5: Área total cultivada com cana-de-açúcar e apta para expansão do cultivo de cana-de açúcar no Centro-Oeste (hectares), 2009

\begin{tabular}{l|c|c|c|c}
\hline \multicolumn{1}{c|}{ Estados } & Área total & $\begin{array}{c}\text { Área cultivada } \\
\text { com cana-de- } \\
\text { açúcar }\end{array}$ & $\begin{array}{c}\text { Área apta para } \\
\text { expansão }\end{array}$ & $\begin{array}{c}\text { Porcentagem } \\
\text { para expansão }\end{array}$ \\
\hline Goiás & 34.008 .669 & 401.800 & 12.600 .530 & $3036 \%$ \\
\hline Mato Grosso do Sul & 35.712 .496 & 275.800 & 10.869 .820 & $3841 \%$ \\
\hline Mato Grosso & 90.335 .790 & 223.200 & 6.812 .854 & $2952 \%$ \\
\hline Centro-Oeste & 160.056 .955 & 900.800 & 30.283 .204 & $3262 \%$ \\
\hline \hline
\end{tabular}

Fonte: Shikida (2013).

\footnotetext{
${ }^{2}$ Os percentuais da produção de cada cultura foram calculados dividindo a quantidade produzida de cada uma das culturas consideradas pela quantidade total produzida daquelas três culturas em todo o estado de Goiás e multiplicando por 100 .
} 
O estado de Goiás apresenta, de um lado, aspectos naturais considerados positivos para o fortalecimento da competitividade, e, de outro lado, aspectos negativos que prejudicam a capacidade do setor produtivo na exploração de seus potenciais. As boas condições para a produção agrícola, a abundante disponibilidade de insumos e a alta tecnologia podem ser comprometidas pelas precárias condições de logística e de infraestrutura para o escoamento da produção do estado (OTTO; NEVES; PINTO, 2012).

Desta maneira, a posição geográfica do estado não é suficiente para compensar a frágil infraestrutura de transporte rodoviário. Entretanto, a localização privilegiada de Goiás viabiliza o recebimento de insumos e de matéria-prima (fornecimento de cana-deaçúcar, máquinas e equipamentos, fertilizantes e adubos etc.) e também o escoamento da produção (álcool e açúcar) (OTTO; NEVES; PINTO, 2012).

Apesar dos esforços de manutenção das estradas que ligam aos principais eixos logísticos do estado como a BR 153, a BR 452, a GO 040 e a GO 060, os investimentos nas malhas rodoviárias são insuficientes e comprometem em parte a logística de transporte. A ferrovia Norte-Sul será um importante corredor para o escoamento da produção quando estiver em operação. A hidrovia Tietê-Paraná já escoa parcialmente a produção de açúcar, embora necessite elevar sua capacidade, além de disponibilizar barcaças para o transporte de etanol (Transpetro). Outro exemplo é a construção do alcoolduto de Senador Canedo (GO) a Paulínia (SP) (cerca de 1.150 km). Além disso, o trecho Ribeirão Preto a Paulínia (206 km) entrou em funcionamento em 2014, enquanto o trecho de Uberaba a Ribeirão Preto está sendo construído, conforme apresentado na figura 1 . O projeto tem previsão de redução de 40\% no custo de transporte até o Porto de Santos (SP) (OTTO; NEVES; PINTO, 2012; CARVALHO, 2008; MARQUES POSTAL, 2014).

Figura 1 - Sistema Integrado de Logística de Etanol

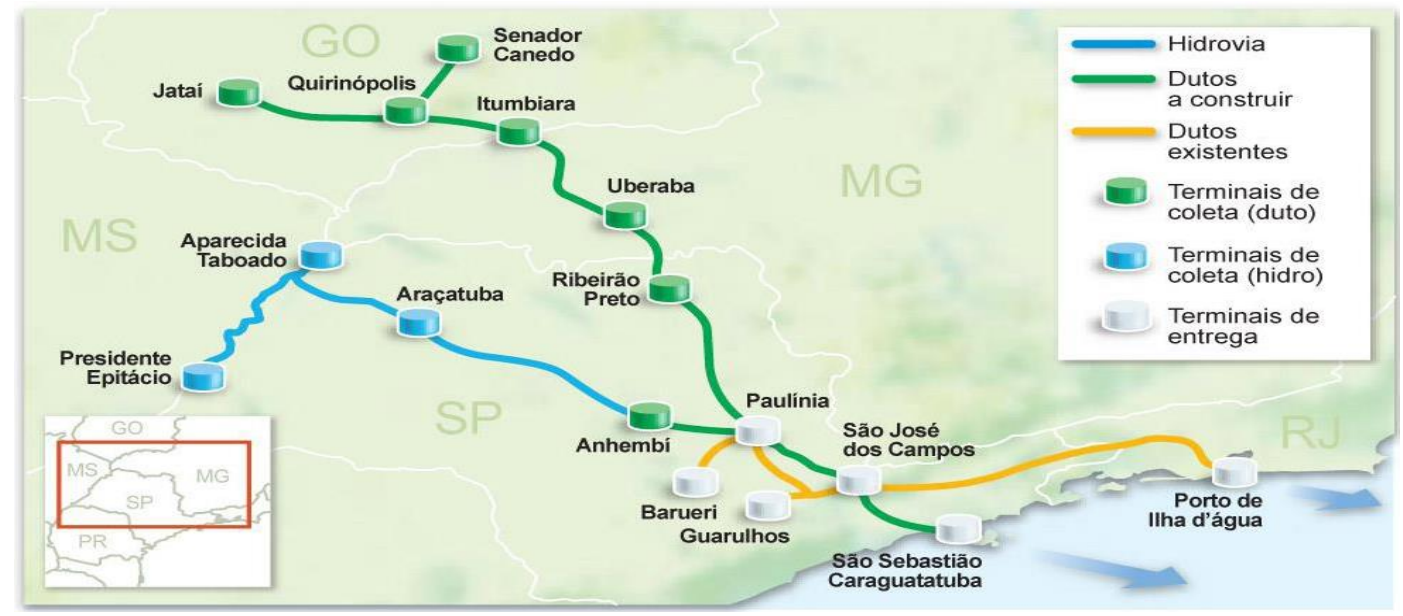

Fonte: Marques Postal (2014, p. 37). 
As condições logísticas podem explicar, em grande medida, a localização das usinas e das destilarias, bem como a concentração da produção canavieira em determinadas regiões do estado (na mesorregião Sul goiano e Centro goiano) para o escoamento da produção de álcool. Isto explica por que as unidades industriais estão localizadas nas proximidades das principais rodovias estaduais e federais, além das hidrovias, ferrovias e do futuro alcoolduto que ligará o estado de Goiás ao estado de São Paulo.

Marques Postal (2014) aponta que a rápida mecanização da colheita da cana-deaçúcar em Goiás foi favorecida pela política estabelecida pelo ZAEcana em vários aspectos: i) a escassa oferta de mão de obra em Goiás; ii) os ganhos de escala com maior produtividade; e iii) o aproveitamento da biomassa para produção de energia oriunda da cogeração com o estímulo da produção a partir da colheita da cana-de-açúcar crua sem queima. O nível de mecanização da colheita em Goiás é de 92,4\%, enquanto que em São Paulo, estado tradicional na produção de cana-de-açúcar é de 88,8\%. Destaque-se que São Paulo foi um dos primeiros estados a adotar tal estratégia devido o protocolo ambiental.

O desenvolvimento tecnológico recente elevou o nível de mecanização de diversas operações de plantio e colheita de cana-de-açúcar, com a consequente redução do número de trabalhadores na atividade comparada a outras culturas, principalmente, aquelas oriundas da agricultura familiar. Nas regiões de relevo mais plano, como é o caso da região Centro-Oeste, tende-se a intensificar o processo de mecanização, elevando ainda mais o problema do desemprego. Outra questão que pode influenciar no emprego está ligada aos acordos previstos no protocolo agroambiental, que prevê o fím da queima dos canaviais. Consequentemente, tais medidas resultam na eliminação gradativa da colheita manual em áreas com topografia limitada em $12 \%$, o que altera drasticamente a composição do emprego na atividade, com o aumento percentual de tratoristas (operadores de colheitadeiras) e de trabalhadores remanejados para a área administrativa (PEROSA, 2014).

Assim, a implantação do ZAEcana a partir de 2009 abriu espaço para a movimentação em direção à ocupação de novas áreas, principalmente, na região CentroOeste, onde existem as maiores extensões planas e aptas ao cultivo e a colheita mecanizada da cana-de-açúcar (condições edafoclimáticas e solos favoráveis). Em Goiás, a expansão da cana-de-açúcar seguiu esta lógica do clima e do solo, aproveitando a topografia plana (conforme o ZAEcana defende) e o potencial tecnológico da colheita mecanizada, com a eliminação da queimada e o aproveitamento da biomassa para a produção de energia, em razão da escassez da mão de obra local no corte manual.

\section{Metodologia}

O presente trabalho utiliza o quociente locacional (QL) como método para analisar o grau de especialização na produção de cana-de-açúcar, dos municípios do estado de Goiás. Esta metodologia é tradicionalmente utilizada para realizar a análise de localização e de especialização da produção de qualquer setor em uma região em relação a sua participação na economia de referência. 
Formulado por Walter Isard e mais tarde utilizado por Haddad (1989), o quociente locacional (QL) é o principal método de cálculo de especialização produtiva utilizado em economia regional, tendo como objetivo identificar especializações e ser um indicador de localização. Lima e Simões (2010) apontam que, ao empregar uma análise relativa, o QL pode não apresentar a realidade local e beneficiar pequenas localidades, sendo uma limitação central do indicador.

Ademais, Crocco et al. (2006) e Suzigan et al. (2003) apontam restrições na utilização do QL por expor um quociente alto para municípios que apresentam poucas unidades produtivas. Outro efeito é apresentar o índice relativamente baixo para um município que possui elevada participação no setor. Assim, as diferenças regionais existentes numa região em análise fazem com que o uso do índice necessite de cautela.

Marion Filho e Oliveira (2011) utilizaram o quociente locacional (QL) para encontrar o grau de especialização na produção de leite no Rio Grande do Sul. Este indicador emprega o valor da produção de um determinado produto pelo valor total adicionado de produtos, ou seja, uma variável de produção de forma agregada. Portanto, através do coeficiente locacional pode-se determinar a distribuição espacial da produção, as regiões onde estão ocorrendo especialização da produção e as que são especializadas.

No presente estudo, optou-se por utilizar o valor total da produção de cana-de-açúcar por município em Goiás e para o estado. Como variável agregada da produção foi utilizada o valor adicionado na agricultura, pois contempla todo o setor agrícola da região analisada. A fórmula do quociente locacional utilizada por Haddad (1998) pode ser apresentada como:

$$
Q L=((V P C j / V A A j)) /((V P C G O / V A A G O))
$$

VPC $\mathrm{j}=$ valor da produção de cana-de-açúcar no município $\mathrm{j}$;

$\mathrm{VAAj}=$ valor adicionado na agricultura do município $\mathrm{j}$;

VPCGO = valor da produção de cana-de-açúcar em Goiás; e, VAAGO = valor adicionado na agricultura de Goiás.

Para interpretar os resultados, foi utilizado o ponto de controle $\mathrm{QL} \geq 2$. Segundo Marion Filho e Oliveira (2011), a não especialização é indicada por QL $<1,1<\mathrm{QL}<2$ indica que existe indícios de especialização, e $\mathrm{QL} \geq 2$ indica especialização produtiva. Portanto, a análise a partir do quociente locacional (QL) do setor canavieiro na região $\mathrm{j}$ ocorrerá da seguinte forma: $\mathrm{QL}<1$, o município $j$ no setor canavieiro não é especializado na produção de cana-de-açúcar; $1<\mathrm{QL}<2$, o município $j$ no setor canavieiro apresenta indícios de especialização na produção de cana-de-açúcar; e, $Q L \geq 2$, o município j no setor canavieiro é especializado na produção de cana-de-açúcar.

Os dados utilizados para o cálculo do QL são disponibilizados pelo Instituto Mauro Borges $^{3}$ (IMB) . As variáveis utilizadas foram: valor da produção de cana-de-açúcar

\footnotetext{
${ }^{3}$ Ver em <http://www.imb.gov.br>.
} 
municipal e estadual; valor adicionado na agricultura; e, valor da produção em toneladas, sendo os valores monetários constantes para o ano de referência de 2010.

\section{Resultados e Discussões}

Já definida a importância da cultura de cana-de-açúcar para o estado de Goiás, resta analisarmos como é a sua distribuição espacial. Além da análise do QL por município, objetivo central deste trabalho, foi incluída uma tabela (ver tabela 6) com dados de QL, para as microrregiões de Goiás, para se ter uma noção preliminar mais agregada a respeito do grau de especialização na produção canavieira. A tabela 6 apresenta o valor do QL para os anos de 2005 e 2015, buscando analisar o grau de especialização das microrregiões e sua distribuição espacial. As microrregiões com $\mathrm{QL} \geq 1$ aparecem destacadas em negrito, indicando indícios de especialização.

De forma geral, cinco microrregiões se destacaram, em 2005, com QL $\geq 1$, o que indica que elas são mais especializadas na produção de cana-de-açúcar que o estado de Goiás. Três estão na mesorregião do Centro goiano - Anápolis, Anicuns e Ceres - enquanto as outras duas, Meia Ponte e Vale do Rio dos Bois, estão no Sul goiano. Porém, apenas duas destas apresentaram QL $\geq 2$ (indicando especialização). Assim, o cálculo do QL indica a especialização em duas delas e uma tendência nas outras três que se destacaram. As treze demais microrregiões não apresentaram indícios de especialização. Em 2015, o quadro se alterou, uma microrregião apresentou indício de especialização - a Vale do Rio dos Bois e outras três com QL $\geq 2$-Ceres, Meia Ponte e Quirinópolis - indicaram estarem especializadas. Isto revela a importância do setor canavieiro nestas microrregiões em relação às demais, já que este ramo da economia possui maior peso nestas regiões.

O desempenho destas microrregiões goianas em termos do grau de especialização da produção da cana-de-açúcar pode ser explicado através das diversas teorias sobre o desenvolvimento regional. A teoria de August Lösch traz o conceito de localização ótima para a firma, buscando reduzir os custos de produção e de transporte e, em conjunto com a teoria de Walter Isard, que aborda o crescimento demográfico, fatores tecnológicos e a subutilização de recursos naturais como fontes do desenvolvimento de uma região. Ao analisar as microrregiões goianas que se destacaram em 2015 na cultura abordada, verificase que elas estão situadas em locais com recursos naturais abundantes e com boas vias de transportes, corroborando os autores citados, indicando a grande relevância destes fatores estratégicos para a dinâmica da atividade produtiva.

Outro ponto de convergência com a teoria de desenvolvimento regional é o crescimento econômico decorrente do setor sucroalcooleiro se manifestando de forma desigual no território, principalmente, por estas regiões já possuírem estrutura produtiva similar à cultura canavieira, disponibilidade de recursos naturais e humanos. 
Tabela 6: Quociente Locacional das microrregiões goianas 2005 e 2015

\begin{tabular}{l|c|c}
\hline \hline Microrregião & QL - 2005 & QL - 2015 \\
\hline Anápolis & $\mathbf{1 . 4 9}$ & 0.52 \\
\hline Anicuns & $\mathbf{2 . 5 5}$ & 0.88 \\
\hline Aragarças & 0.01 & 0.17 \\
\hline Catalão & 0.17 & 0.2 \\
\hline Ceres & $\mathbf{7 . 2 6}$ & $\mathbf{2 . 6 6}$ \\
\hline Chapada dos Veadeiros & 0.13 & 0.02 \\
\hline Entorno de Brasília & 0.25 & 0.35 \\
\hline Goiânia & 0.15 & 0.02 \\
\hline Iporá & 0.01 & 0.05 \\
\hline Meia Ponte & $\mathbf{1 . 4 7}$ & $\mathbf{2}$ \\
\hline Pires do Rio & 0.01 & 0 \\
\hline Porangatu & 0.02 & 0.16 \\
\hline Quirinópolis & 0 & $\mathbf{4 . 5 2}$ \\
\hline Rio Vermelho & 0.01 & 0 \\
\hline São Miguel do Araguaia & 0.01 & 0 \\
\hline Sudoeste & 0.85 & 0.95 \\
\hline Vale do Rio dos Bois & $\mathbf{1 . 5 8}$ & $\mathbf{1 . 8}$ \\
\hline Vão do Paranã & 0.15 & 0.07 \\
\hline \hline
\end{tabular}

Fonte: Elaboração própria, com base nos dados do IMB.

Neste mesmo sentido, vale considerar que Ceres é a microrregião mais importante em 2005, pois, produziu 5.081.020 toneladas, o equivalente a 32,48\% da produção total goiana, apresentando um QL de 7,26. Por outro lado, em 2015, a quantidade produzida subiu para 7.002.324 toneladas, mas representou apenas 9,71\% da produção, e um QL de 2,66 . Estes dados indicam que, embora a região seja especializada, a produção da cana-deaçúcar aumentou relativamente mais no estado como um todo do que nesta microrregião específica.

A microrregião de Quirinópolis se destacou em 2015 por apresentar produção total de cana-de-açúcar de 14.428 .310 toneladas, ou seja, $20 \%$ da quantidade produzida em Goiás. Além disso, em 2005, foram abertas duas usinas no município sede desta microrregião, o que deu início à expansão da atividade no período. O quociente apresentado em 2015 foi o maior apresentado em Goiás - 4,52 - evidenciando o processo de 
especialização da região. Além disso, três entre os 10 municípios mais especializados se encontram nesta região (ver tabela 7).

O QL é a principal forma de se verificar o grau de especialização produtiva, porém ele permite que outros fatores afetem seu cálculo por ser uma medida relativa. Deste modo, poucos municípios de uma microrregião podem estar afetando aquele índice positivamente ou negativamente. Para verificar possíveis distorções em relação ao grau de especialização microrregional, foi calculado o QL a nível municipal e os dados foram espacializados para que se possa ter uma visão preliminar geral da possível concentração da atividade produtiva no estado de Goiás para os dois anos considerados (figuras 2 e 3 ).

Na elaboração dos mapas, os municípios foram agrupados em três grandes categorias definidas da seguinte forma: municípios com QL $<1$ estão representados pela cor mais clara da legenda; a categoria com cor intermediária contempla os municípios com $1 \leq \mathrm{QL}<2$ (ou seja, municípios com indícios de especialização); e, a categoria representada pela cor mais escura engloba os municípios com QL $\geq 2$ (ou seja, municípios especializados).

\section{Figura 2: Distribuição espacial do QL canavieiro dos municípios goianos - 2005}

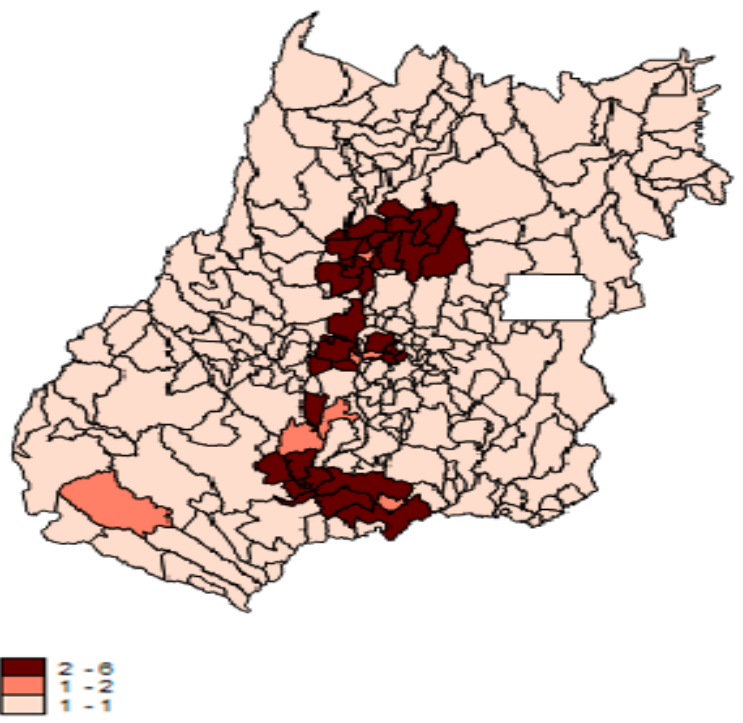

Fonte: Elaboração própria através da base de dados do IMB.Construção e visualização de mapas através do Software Stata.

A análise dos mapas permite inferir que há uma grande concentração produtiva em 2005 na mesorregião do Centro de Goiás (nas microrregiões de Ceres e Anápolis) e que a mesma permanece em 2015. Neste último ano, verifica-se que os municípios da mesorregião Sul aumentam o seu grau de especialização, o que indica que a produção canavieira se tornou cultura predominante e cresceu em representatividade também nesta localidade (nas microrregiões de Meia Ponte, Quirinópolis e Vale do Rio dos Bois). Este 
aumento do grau de especialização dos municípios do Sul goiano pode estar associado a efeitos da estratégia de zoneamento agroecológico, bem como aos estímulos advindos de incentivos fiscais estaduais e federais como já mencionado.

\section{Figura 3: Distribuição espacial do QL canavieiro dos municípios goianos - 2015}
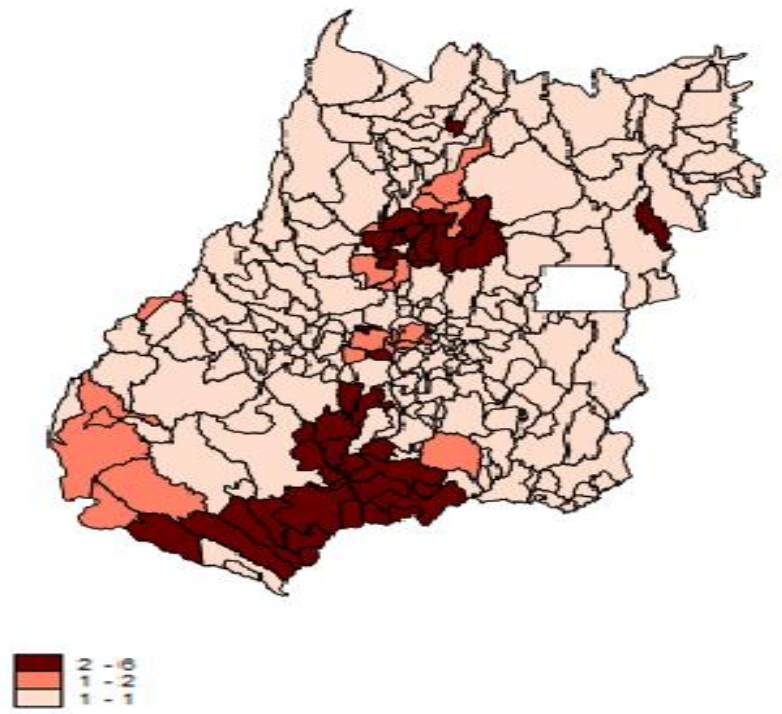

Fonte: Elaboração própria através da base de dados do IMB.Construção e visualização de mapas através do Software Stata.

Como verificado, é possível afirmar que há uma grande concentração produtiva da cultura de cana-de-açúcar em Goiás e para facilitar a análise das tabelas seguintes, que trazem informações à nível municipal, serão considerados somente os 25 municípios com maior grau de especialização em cada um dos anos considerados. Isso se justifica pelo fato de que, como já foi demonstrado nos mapas, a maior parte dos municípios de Goiás apresentam QL < 1, não havendo nem ao menos indícios de especialização. De um total de 246 municípios, 41 municípios apresentaram indícios de especialização $(1<\mathrm{QL}<2)$ e somente 35 foram caracterizados como especializados, ou seja, apresentaram QL $\geq 2$, tanto em 2005 quanto em 2015.

A tabela 7, apresentada na sequência elenca os municípios mais especializados na produção de cana-de-açúcar em 2005.

Quando inclui na análise apenas os 25 minicípios mais especializados em 2005 (tabela 7), verifica-se a predominância da microrregião de Ceres, com 14 municípios. Os demais estão localizados nas microrregiões do Sul e do Centro de Goiás. A posição significativa dos municípios da microregião de Ceres ocorre devido, ainda que de forma incipiente, à introdução desta cultura, na região, na década de 1930, além da qualidade da 
infraestrutura local e das terras, propulsores gerados pela proximidade de Brasília e Goiânia. Os demais municípios estão dispersos nas microrregiões do Sul e Centro Goiano, com exceção apenas de Vila Propício que está no entorno de Brasília.

Tabela 7: Municípios goianos em ordem de grau de especialização (2005)

\begin{tabular}{|c|c|c|c|}
\hline Município & Microrregião & QL - 2005 & QL - 2015 \\
\hline Goianésia & Ceres & 13.25 & 4.48 \\
\hline Maurilândia & Sudoeste de Goiás & 11.46 & 4.51 \\
\hline Nova Glória & Ceres & 11.23 & 6.35 \\
\hline Carmo do Rio Verde & Ceres & 11.21 & 3.25 \\
\hline Ipiranga de Goiás & Ceres & 10.86 & 3.17 \\
\hline Americano do Brasil & Anicus & 10.4 & 3.42 \\
\hline São Luiz do Norte & Ceres & 9.24 & 6.06 \\
\hline Rialma & Ceres & 9.12 & 4.35 \\
\hline São Patrício & Ceres & 9.1 & 2.9 \\
\hline Santa Helena de Goiás & Sudoeste de Goiás & 8.81 & 3.12 \\
\hline Turvelândia & Vale do Rio dos Bois & 8.58 & 3.12 \\
\hline Barro Alto & Ceres & 7.61 & 4.69 \\
\hline Brazabantes & Anápolis & 7.21 & 1.24 \\
\hline Castelândia & Sudoeste de Goiás & 7.13 & 2.59 \\
\hline Anicus & Anicus & 6.92 & 1.28 \\
\hline Porteirão & Meia Ponte & 6.72 & 4.28 \\
\hline Itapaci & Ceres & 6.11 & 2.46 \\
\hline Rubiataba & Ceres & 5.9 & 2.07 \\
\hline Vila Propício & Entorno de Brasília & 4.88 & 3.81 \\
\hline $\begin{array}{c}\text { Santa Rita do Novo } \\
\text { Destino } \\
\end{array}$ & Ceres & 4.68 & 1.76 \\
\hline Jandaia & Vale do Rio dos Bois & 4.14 & 2.3 \\
\hline Santo Antônio de Goiás & Goiânia & 4.05 & 0 \\
\hline Inhumas & Anápolis & 3.97 & 1.45 \\
\hline Goiatuba & Meia Ponte & 3.88 & 2.67 \\
\hline Nova América & Ceres & 3.86 & 1.1 \\
\hline
\end{tabular}

Fonte: Elaboração própria com base nos dados do IMB. 
Tabela 8: Municípios goianos em ordem de grau de especialização (2015)

\begin{tabular}{|c|c|c|c|}
\hline Município & Microrregião & QL -2005 & QL - 2015 \\
\hline Gouvelândia & Quirinópolis & 0,00 & 7,36 \\
\hline Nova Glória & Ceres & 11,23 & 6,35 \\
\hline São Luiz do Norte & Ceres & 9,24 & 6,06 \\
\hline Quirinópolis & Quirinópolis & 0,00 & 5,83 \\
\hline Paranaiguara & Quirinópolis & 0,00 & 4,75 \\
\hline Barro Alto & Ceres & 7,61 & 4,69 \\
\hline Aporé & Sudoeste de Goiás & 0,00 & 4,65 \\
\hline Maurilândia & Sudoeste de Goiás & 11,46 & 4,51 \\
\hline Goianésia & Ceres & 13,25 & 4,48 \\
\hline Rialma & Ceres & 9,12 & 4,35 \\
\hline Porteirão & Meia Ponte & 6,72 & 4,28 \\
\hline Cachoeira Dourada & Meia Ponte & 0,00 & 4,05 \\
\hline São Simão & Quirinópolis & 0,00 & 4,04 \\
\hline Rianápolis & Ceres & 0,06 & 3,95 \\
\hline Caçu & Quirinópolis & 0,00 & 3,95 \\
\hline Vila Propício & Entorno de Brasília & 4,88 & 3,81 \\
\hline Edeia & Vale do Rio dos Bois & 0,00 & 3,75 \\
\hline Inaciolândia & Meia Ponte & 0,36 & 3,67 \\
\hline Itumbiara & Meia Ponte & 2,65 & 3,63 \\
\hline Vila Boa & Entorno de Brasília & 0,03 & 3,62 \\
\hline Acreúna & Vale do Rio dos Bois & 1,48 & 3,45 \\
\hline Americano do Brasil & Anicuns & 10,40 & 3,42 \\
\hline Santa Isabel & Ceres & 2,36 & 3,40 \\
\hline Carmo do Rio Verde & Ceres & 11,21 & 3,25 \\
\hline Ipiranga de Goiás & Ceres & 10,86 & 3,17 \\
\hline
\end{tabular}

Fonte: Elaboração própria com base nos dados do IMB.

Em 2015, a produção canavieira se torna menos especializada nos municípios que se destacaram em 2005, e se torna mais dispersa no território goiano. A tabela 8 destaca os 25 municípios com maior quociente em 2015, estando concentrados nas mesorregiões do Centro e Sul, sendo que a mesorregião Sul Goiano se destaca por ganhar espaço entre as 
regiões especializadas devido, principalmente, estarem próximas à importantes rodovias federais e, por conta, da instalação de usinas de moagem nestas localidades.

Por conseguinte, a microrregião de Quirinópolis é a que mais se distingue entre as demais em termos de especialização produtiva em 2015. Esta microrregião foi a que mais municípios se destacaram como, por exemplo, o de Gouvelândia que apresentou o maior quociente locacional goiano -7,36 - produzindo 2.504.764 toneladas de cana-de-açúcar em 2015, resultando numa expansão da atividade igual a 590,53\% no período analisado. Enquanto isso, o município de Quirinópolis foi o que obteve maior produção, totalizando 6.758.505 toneladas. Além disso, os municípios de Paranaiguara, São Simão e Caçu, que não tiveram produção canavieira em 2005 e em 2015, apresentaram expansão do complexo sucroalcooleiro e se tornaram especializados nesta cultura, assim como o ocorrido em municípios de outras regiões como, por exemplo, Aporé, Cachoeira Dourada e Edeia.

Em suma, conforme se observa nas tabelas 7 e 8, os municípios da mesorregião do Centro goiano perderam graus em seu nível de especialização na produção de cana-deaçúcar no período, enquando os municípios do Sul goiano aumentaram sua especialização. Entre as razões que explicam a especialização no Sul de Goiás estão os incentivos fiscais e o zoneamento agroecológico da cana-de-açúcar, sendo que este indicou estas regiões como as mais aptas e, logo, com os solos mais produtivos.

\section{Considerações Finais}

O setor primário, exclusivamente a agropecuária, é de grande importância econômica para Goiás, participando com 10,4\% do PIB total do estado (IMB, 2016). Evidenciou-se a relevância do complexo agroindustrial sucroalcooleiro para a economia goiana e que ele é um importante setor gerador de renda e emprego a partir dos efeitos espaciais de transbordamento local onde a cultura canavieira se encontra instalada. Assim, o presente trabalho se propôs a analisar o grau de especialização da produção de cana-deaçúcar nos municípios goianos, nos anos de 2005 e 2015, haja vista a política de incentivos fiscais para a atração de investimentos do setor sucroalcooleiro para o estado a partir de 2003.

Uma das principais contribuições desse trabalho foi a análise da evolução histórica da cadeia da cana-de-açúcar em Goiás conjugada com a avaliação do grau de especialização desta cultura no estado, por meio da aplicação do quociente locacional em nível municipal no setor canavieiro, o que permite avaliar a distribuição da produção e a planejar políticas públicas para as regiões desfavorecidas economicamente.

Os resultados apontaram para uma crescente especialização dos municípios goianos, especialmente nas mesorregiões do Sul e Centro goiano, o que indica que houve um aprofundamento da desigualdade regional quando se avalia a cultura da cana-de-açúcar, já que, de forma geral, as demais regiões de Goiás não apresentaram quocientes significativos. Destaca-se que, a maior parte dos municípios que apresentaram mudança em sua matriz produtiva está localizada na mesorregião do Sul goiano e, na qual está a microrregião de 
Quirinópolis, com o município de Quirinópolis, que foi o maior produtor goiano, e município de Gouvelândia, que foi o que obteve o maior quociente no estado para o período

Especificamente sobre o QL, os municípios goianos que apresentaram aumento da especialização na produção de cana-de-açúcar passaram de 35 para 41 e, destes, 13 se destacam por atingir QL superior a 4, ou seja, um nível alto de especialização, a saber: Gouvelândia $(7,36)$, Nova Glória $(6,34)$, São Luiz do Norte $(6,06)$, Quirinópolis $(5,82)$, Paranaiguara (4,74), Barro Alto (4,68), Aporé $(4,64)$, Maurilândia $(4,50)$, Goianésia $(4,48)$, Rialma (4,34), Porteirão $(4,28)$, São Simão $(4,04)$ e Cachoeira Dourada $(4,04)$. Estes municípios se caracterizam por estarem próximos de centros populacionais e por terem solos aptos e produtivos para a cana-de-açúcar. Embora estes sejam caracterizados como altamente especializados, não se pode dizer que eles são dependentes do setor sucroalcooleiro, pois o quociente é um indicador relativo e regiões dinâmicas se tornaram especializadas nesta cultura.

A elevação da especialização da produção de cana-de-açúcar naqueles municípios pode ser explicada por vários fatores determinantes que podem estar relacionados aos maiores ganhos de escala, oriundos das inovações tecnológicas e, sobretudo, da competitividade da cadeia canavieira em relação às regiões mais tradicionais. Isto inclui: políticas públicas de incentivo ao consumo de álcool (etanol); política de incentivos fiscais (Programa Produzir/Fomentar) e de crédito (FCO) do governo estadual e também do governo federal (BNDES); o processo de saturação do setor sucroalcooleiro nos municípios tradicionais do Nordeste e de São Paulo; o problema das deseconomias de escala e capacidade ociosa instalada dos grandes grupos e empresas; a maior disponibilidade e abundância de terras mais baratas de alta produtividade; o zoneamento ZAEcana, que revelou a existência de áreas disponíveis para a expansão da cana-de-açúcar em Goiás, Minas Gerais, Mato Grosso e Mato Grosso do Sul; a exigência da mecanização de todas as etapas do processo produtivo da cadeia canavieira pelos projetos greenfields; e, a maior proximidade das usinas e destilarias da infraestrutura rodoviária, ferroviária, aeroviária e logística, embora seja ainda considerada bastante frágil e insuficiente.

Conclui-se que o estado de Goiás apresenta municípios especializados na produção de cana-de-açúcar, sendo que estes estão localizados principalmente nas mesorregiões do Centro e do Sul Goiano. Estas duas regiões são as mais dinâmicas e possuem cadeias produtivas modernas. Pelo fato de o quociente locacional ser uma medida relativa, o estudo permite afirmar com certa segurança que a especialização da produção de cana-de-açúcar se consolidou em alguns municípios já especializados nesta cultura e em outros municípios geograficamente próximos àqueles também estão se especializando, indicando a existência de polos de crescimento que tenderam a se perpetuar ao longo do período analisado. Por fim, a melhoria das condições de infraestrutura das mesorregiões localizadas fora dos polos de crescimento seria de grande importância no sentido de estimular o crescimento econômico das mesmas e, logo, inseri-las na dinâmica produtiva. 


\section{Referências}

ABDALA, Klaus de Oliveira; RIBEIRO, Francis Lee. Análise dos impactos da competição pelo uso do solo no estado de Goiás durante o período 2000 a 2009 provenientes da expansão do complexo sucroalcooleiro. Revista Brasileira de Economia, Rio de Janeiro, v. 65, n. 4, p 373-400, out./dez. 2011. http://dx.doi.org/10.1590/S0034-71402011000400004

BATISTA, Fabiana. Rendimento da cana cai 6,3\% nas usinas. Gazeta Mercantil, jul. 2008. Disponível em: <https://www.agrolink.com.br/noticias/rendimento-da-cana-cai-6-3--nasusinas_71675.html>. Acesso em: 21 out. 2018.

BORGES, Barsanufo Gomides. A expansão da fronteira agrícola em Goiás. História Revista, Goiânia, v. 1, n. 2, p. 35-45,jul/dez, 1996. Disponível em: <http://www.revistas.ufg.br/index.php/historia/article/view/10932 > Acesso em 6 de outubro de 2018. https://doi.org/10.5216/hr.v1i2.10932

CARVALHO, S. P. de. Agricultura familiar e agroindústria canavieira: integrações e contradições Dissertação de Mestrado, 2008. Universidade Federal de Goiás UFG: Goiás, 2008.

Disponível

em:

<https://portais.ufg.br/up/170/o/agricultua_familiar_e_agroindustria_canavieira.pdf.> Acesso em: 13, mai.2015.

SIMÕES DE CASTRO, S., ABDALA, K., APARECIDA SILVA, A., \& BORGES, V. A expansão da cana-de-açúcar no cerrado e no estado de Goiás: elementos para uma análise espacial do processo. Boletim Goiano de Geografia, Goiânia, v. 30, n. 1, p. 171-191, jan./jun. 2010. https://doi.org/10.5216/bgg.v30i1.11203

CROCCO, M.; GALINARI, R.; SANTOS, F.; LEMOS, M. B.; SIMÕES, R. Metodologia de identificação de aglomerações produtivas locais. Nova Economia, Belo Horizonte, v. 16, n. 2, p. 211-241, mai./ago. 2016.

DIAS, Rafael Guimarães. Padrão Distribuição Espacial do PIB Agropecuário entre os Municípios do Estado de Goiás: Uma análise exploratória em 1999 a 2009. 2013. Monografia (Graduação em Ciências Econômicas) - Faculdade de Administração, Ciências Econômicas e Ciências Contábeis, Universidade Federal de Goiás, Goiânia, 2013.

ESTEVAM, Luís Antônio. Agricultura Tradicional em Goiás. In PEREIRA, Diamantino Alves. Agricultura de Goiás - Análise \& Dinâmica. Goiânia: UCG, 2004.

GREMAUD, Amaury; VASCONCELLOS, Marco Antônio; TONETO, Rudinei Júnior. Economia Brasileira Contemporânea. 7. ed.. São Paulo: Editora Atlas, 2007.

HADDAD, Paulo Roberto. Medidas de localização e de especialização. In: Economia Regional: Teorias e Métodos de Análise (org). Fortaleza: BNB/ETENE, 1989, p. 67-206. 
IBGE. INSTITUTO BRASILEIRO DE GEOGRAFIA E ESTATÍSTICA. Produção Agrícola Municipal 2005 e 2015. Rio de Janeiro, 2016. Disponível em: https://sidra.ibge.gov.br/pesquisa/pam/tabelas. Vários Acessos.

IMB. INSTITUTO MAURO BORGES. Dados da agropecuária de 2005 e 2015. Goiânia, GO, 2016. Disponível em: https://www.imb.go.gov.br/bdel. Vários acessos.

LIMA, Ana Carolina; SIMÕES, Rodrigo. Centralidade e Emprego na Região Nordeste do Brasil no período de 1995 a 2007. Nova Economia, Belo Horizonte, v. 20, n. 1, p. 39 83, 2010.

LIMA, Ana Carolina da Cruz; SIMÕES, Rodrigo Ferreira. Teorias do Desenvolvimento Regional e suas Implicações de Política Econômica no Pós-Guerra: O Caso Brasil. Belo Horizonte: CEDEPLAR/FACE/UFMG, 2009.

MANZATTO, C. V.; ASSAD, E. D.; BACA, J. F. M.; ZARONI, M. J.; PEREIRA, S. E. M.. Zoneamento Agroecológico da Cana-de-Açúcar: expandir a produção, preservar a vida, garantir o futuro. Ministério da Agricultura, Pecuária e Abastecimento. Rio de Janeiro, documentos 110, Embrapa Solos, set. 2009. Disponível em: http://www.mma.gov.br/estruturas/182/_arquivos/zaecana_doc_182.pdf >. Acesso em: 25, set. 2018.

MARION FILHO, Pascoal José; OLIVEIRA, Luiz Fernando Valter. A especialização e a concentração da produção da produção de leite nas microrregiões do Rio Grande do Sul (1990-2007). Ensaios FEE, Porto Alegre, v. 31, Número Especial, p. 635-647, jun. 2011.

https://doi.org/10.25070/rea.v9i2.185

MARQUES POSTAL, A. C. Acesso a Cana-de-açúcar na Expansão Sucroenergética Brasileira do pós 2000: o caso de Goiás. Campinas, SP: [s/n], 2014. Dissertação (Mestrado) - Universidade Estadual de Campinas. Instituto de Economia. Disponível em: $<$ http://www.bibliotecadigital.unicamp.br/document/?code=000936512 $>$ Acesso em: 3 jun. 2015.

NASSAR, A M.; RUDORFF, B. F.T.; ANTONIAZZI, L. B.; AGUIAR de D. A.; BACCHI M. R. P. \& ADAMI M.; Prospects of the sugarcane expansion in Brazil: impacts on direct and indirect land use changes. In: ZUURBIER, P. e VOOREN, J.V. (Org). Sugarcane Ethanol: contributions to climate change mitigation and the environment. Laxenburg: Wageniguen Academic Publishers, 2008. p. 63-94.

OTTO, I. M. C.; NEVES, M.F.; PINTO, M. J. A. Cadeia produtiva sucroenergética FIEG. Goiânia, 2012.

PEROSA, Bruno Berzanquen. Impactos da Expansão Canavieira. Revista Agroanalysis, Jan. 2014. Disponível em: <www.agroanalysis.com.br〉. Acesso em: 06 mar 2015. 
QUEIROZ, Antônio Marcos de. Estruturas de governança no complexo agroindustrial sucroalcooleiro goiano. Uberlândia-MG: [313 p], 2016. Tese (Doutorado). Universidade Federal de Uberlândia, 2016.

SAUER, Sérgio; PIETRAFESA, José Paulo. Cana-de-açúcar, financiamento público e produção de alimentos no cerrado. Campo-Território: Revista de Geografia Agrária, Uberlândia, v.7, n. 14, p. 1-29, ago., 2012.

SHIKIDA, Pery. F. A. Expansão canavieira no Centro-Oeste: limites e potencialidades. Revista de Política Agrícola, ano XXII - n. 2 - Abr./Maio/Jun.2013. Disponível em: <http://ainfo.cnptia.embrapa.br/digital/bitstream/item/88489/1>. Acesso em: 15 dez. 2014.

SOUZA, Nali. Desenvolvimento Regional. São Paulo: Editora Atlas, 2009.

SUZIGAN, W.; FURTADO, J.; GARCIA, R.; SAMPAIO, S. E. K. Coeficientes de Gini Locacional - GL: aplicação à indústria de calçados do Estado de São Paulo. Nova Economia, Belo Horizonte, v. 13, n. 2, p. 39-60, 2003.

VIAN, Carlos Eduardo Freitas. Agroindústria Canavieira: estratégias competitivas e modernização. Campinas-SP: Editora Átomo, 2015. 